\title{
Factor XI Deficiency in West Algeria: A Case Report and Literature Review
}

Arabi A*, Chekkal M, Cheref L, Bouchama S, Mehded S, Brahimi M, Yafour N and Bekadja MA

Haematology and Cell Therapy Unit, Etablissement Hospitalier et Universitaire 1er Novembre 1954 Oran, Algeria

*Corresponding author: Arabi Abdessamed, Haematology and Cell Therapy Unit, Etablissement Hospitalier et Universitaire 1er Novembre 1954 Oran, Algeria, Tel: 21304142 14; E-mail: abdessamed.arabi@gmail.com

Received date: June 08, 2015, Accepted date: July 27, 2015, Publication date: July 31, 2015

Copyright: (c) 2015 Arabi A, et al. This is an open-access article distributed under the terms of the Creative Commons Attribution License, which permits unrestricted use, distribution, and reproduction in any medium, provided the original author and source are credited.

\begin{abstract}
Factor XI deficiencies are rare. Initially, they were described only in Ashkenazy Jews with two types of characteristic gene mutation. Now, 152 mutations have been identified, mostly in non-Jewish population.

We report the case of a deficiency identified in Arabic young girl living in West Algeria; gene sequences showed a type II mutation, frequent in Ashkenazy Jews. May be it is coincidence; but it is possible that this finding is related to the migratory story of this region.
\end{abstract}

Keywords: Factor XI; Ashkenazy Jews; Type II mutation

\section{Introduction}

Factor XI (FXI) deficiency was originally described in a Jewish family in the USA and was called "hemophilia C" and distinguish from hemophilia A or B by its occurrence in either sex and the absence of spontaneous bleeding [1].

FXI deficiency is particularly common in Ashkenazi Jews; it is one of the most common genetic disorders in this population with heterozygous frequency of $8 \%$ [2]. The frequency of FXI deficiency in non-Jewish people is unknown, as is the case for Algeria. This bleeding disorder is probably underdiagnosed because patients with severe or partial FXI deficiency do not suffer from spontaneous bleeding but may do so only after haemostatic challenge, generally related to surgery or trauma. In particular, women's are exposed to a haemostatic challenge every month during their menstrual period.

The other common challenge for women is childbirth. Moreover, there is often a poor correlation between bleeding and the baseline FXI clotting activity [3]. Inherited FXI deficiency has now been described in a wide variety of population groups but remains most common in Ashkenazy Jews. In this group, it is estimated that one in eight individuals is heterozygous and one in 190 homozygous for mutations in the FXI gene $[4,5]$.

Most cases of FXI deficiency in Ashkenazi Jews are caused by two distinct mutations, each accounting for $40-50 \%$ of abnormal alleles. These are Glu117Strop referred to as the type II mutation and Phe283Leu, the type III mutation.

The type III mutation occurs almost exclusively in Ashkenazy Jews, but the type II mutation is also found in Iraqi Jews and Arabs, suggesting an earlier ancestral origin [6,7]. Phe283Leu results in impaired dimer formation producing a quantitative deficiency [8]. We report the case of factor XI deficiency discovered in a little girl born in Mostaganem, Western Algerian city.

\section{Materials and Methods}

\section{Patient}

B.K was born in 1997 in Mostaganem; she was referred in haematology in 2008 for exploration of a PTT discovered during preoperative assessment for tonsillectomy. Clinical examination was normal, but medical history was marqued by frequent epistaxis, hematomas after intramuscular injections and ecchymosis. Mennarchies occurs at 11 years old and were very important. Her parents are cousins and she is the youngest of 3 brothers and 3 sisters; no one of them presents any bleeding symptom, and they refuse to be included in screening.

\section{Coagulation assays}

Blood was obtained from the patient, her father and mother after informed consent.

Prothrombin time, a PTT fibrinogen concentration, factor VIII, factor IX and factor XI activities and von Willebrand factor (ristocetin co-factor activity and antigen) were measured with standard assays using the BCS analyser (Dade Behring, Marburg, Germany) and the Vidas analyser (BioMerieux, Marcy l'Etoile, France).

\section{Molecular analyses}

Genomic DNA from the proband, the father and the mother was purified from leucocytes according to standard protocols. The F11 gene was analysed by direct sequencing.

\section{Results}

\section{Coagulation results for the propositus}

\author{
$-\mathrm{aPTT}=74 \mathrm{sec}(\mathrm{T}=31)$ \\ -Prothrombin time $=13 \mathrm{sec}(\mathrm{T}=12)-\mathrm{TP}=82 \%$ \\ -Fibrinogen $=2,5 \mathrm{~g} / \mathrm{L}(\mathrm{N}=2-4)$ \\ - FVIII $=90 \%(\mathrm{~N}=60-150 \%)$
}


-FIX $=100 \%(\mathrm{~N}=60-120 \%)$

-Negative Circulating anticoagulants

-vWF:Ag=85\% (N=50-150\%)

-vWF:Rco $=55 \%(\mathrm{~N}=50-150 \%)$

$-\mathrm{FXI}=10 \%(\mathrm{~N}=70-120 \%)$

\section{Values of FXI of father and mother}

-Father $=40 \%$

-Mother $=30 \%$

\section{Sequence analysis of FXI}

-Propositus=Mutation p.Glu 117 stop homozygous (Type II)

-Father=Mutation p.Glu 117 stop hétérozygous (Type II)

-Mother=Mutation p.Glu 117 stop hétérozygous (Type II)

\section{Discussion}

In the literature, we found no other cases of FXI deficits reported in Algeria; this is abnormal because our country's history is marqued by significant migratory currents of Turkish, Spanish and French people; moreover, after the conquest of Granada by the Catholic in 1492, many Sephardic Jews setted and lived for long time in Algeria, and the consanguine marriages are still frequent.

But we now that FXI deficiency is a rare bleeding disorder that occurs in general population at frequency of one in a million [9]; may be that is the reason why patients do not consult.

As reported [10], FXI deficiency is associated with a variable injuryrelated bleeding diathesis in most severely deficient patients and in $50 \%$ of partially deficient patients. Bleeding is associated with trauma or surgery, and spontaneous bleeding is not typical.

This is the case in our patient; despite a severe deficiency, haemorrhagic signs remains moderate. Several studies have been conducted to evaluate the determinants of bleeding tendency and neither plasma levels of FXI coagulant activity (FXI:C) nor FXI antigen (FXI:Ag) were associated with bleeding. However, bleeding is significantly associated with homozygous type II mutations and compound type II-type III mutations in FXI, resulting in severe deficiency in FXI and low plasma levels. Bleeding is also increased when plasma levels of the von Willebrand factor (VWF) are at the lower end of normal levels [11].

Over $96 \%$ of FXI deficiency is accounted for by two of four common mutations found in Ashkenazi Jews, namely type II (a nonsense mutation in exon 5) and type III (a missense mutation in exon 9) [12].

Yssufumi Manaka and coll. Identified two other mutations in nonJewish population, in case 1 , a $\mathrm{T}$ to $\mathrm{G}$ transition in exon 12 results in the substitution of Phe- 442 by Val (FXLF442V); in case 2 a C to A transition in exon 5 results in the substitution of Cys-128 by a nonsense codon (FXI-C128X) [13].

Anwar Alhaq and colleagues described another mutation in nonJewish population, TGG to TGC transversion in codon 228 of exon 7 (FXI-W228C). This missense mutation results in a Trp to Cys substitution within the third apple domain of FXI [14].
In France, nine others mutations were identified in seven families from the west of France [15]: Q88X het (exon 4), Q88X hom (exon 4), T575M het (exon 15), nt 137 ins G (exon 3), R210X het (exon7), G336R het (exon 10), G581X hom (exon 15), G581X het (exon15) and G350A het (exon 10). Curiously, all these mutations have no different clinical consequences.

To date, 152 mutations in the FXI gene have been reported with four exhibiting founder effects in specific populations, Glu117stop in Ashkenazi and Iraqui Jews and Arabs, Phe283Leu in Ashkenazi Jews, Cys38Arg in Basques, and Cys128stop in the United Kingdom Severe FXI deficiency does not confer protection against acute myocardial infarction, but is associated with reduced incidence of ischemic stroke. Inhibitors to FXI develop in one-third of patients with very severe FXI deficiency following exposure to blood products. Therapy for prevention of bleeding during surgery in patients with severe FXI deficiency consists of plasma, factor XI concentrates, fibrin glue and anti-fibrinolytic agents. In patients with an inhibitor to FXI, recombinant factor VIIa is useful [16].

Concerning Algeria, we think that this case report is the first one published; we hope that it will be not the last; we have to prospect about frequency of FXI deficiency and types of mutations associated, and we are discussing with researchers of the anthropology center for more information about the history of migration in Algeria.

\section{References}

1. Rosenthal RL, Dreskin OH, Rosenthal N (1953) New hemophilia-like disease caused by deficiency of a third plasma thromboplastin factor. Proc Soc Exp Biol Med 82: 171-174.

2. Seligsohn U (1993) Factor XI deficiency. Thromb Haemost 70: 68-71.

3. Bolton-Maggs PH, Patterson DA, Wensley RT, Tuddenham EG (1995) Definition of the bleeding tendency in factor XI-deficient kindreds--a clinical and laboratory study. Thromb Haemost 73: 194-202.

4. Asakai R, Davie EW, Chung DW (1987) Organization of the gene for human factor XI. Biochemistry 26: 7221-7228.

5. Seligsohn U (1978) High gene frequency of factor XI (PTA) deficiency in Ashkenazi Jews. Blood 51: 1223-1228.

6. Goldstein DB, Reich DE, Bradman N, Usher S, Seligsohn U, et al. (1999) Age estimates of two common mutations causing factor XI deficiency: recent genetic drift is not necessary for elevated disease incidence among Ashkenazi Jews. Am J Hum Genet 64: 1071-1075.

7. Peretz H, Mulai A, Usher S, Zivelin A, Segal A, et al. (1997) The two common mutations causing factor XI deficiency in Jews stem from distinct founders: one of ancient Middle Eastern origin and another of more recent European origin. Blood 90: 2654-2659.

8. Meijers JC, Davie EW, Chung DW (1992) Expression of human blood coagulation factor XI: characterization of the defect in factor XI type III deficiency. Blood 79: 1435-1440.

9. Saunders RE, O'Connell NM, Lee CA, Perry DJ, Perkins SJ (2005) Factor XI deficiency database: an interactive web database of mutations, phenotypes, and structural analysis tools. Hum Mutat 26: 192-198.

10. Bolton-Maggs PH, Patterson DA, Wensley RT, Tuddenham EG (1995) Definition of the bleeding tendency in factor XI-deficient kindreds--a clinical and laboratory study. Thromb Haemost 73: 194-202.

11. Guéguen P, Galinat H, Blouch MT, Bridey F, Duchemin J, et al. (2012) Biological determinants of bleeding in patients with heterozygous factor XI deficiency. Br J Haematol 156: 245-251.

12. Blackwell Publishing Ltd. (2004) A Severe factor XI deficiency caused by compound heterozygosity. A British Journal of Haematology 125: 814-820. 
Citation: Arabi A, Chekkal M, Cheref L, Bouchama S, Mehded S, et al. (2015) Factor XI Deficiency in West Algeria: A Case Report and Literature Review. J Blood Disord Transfus S4: S4-003. doi:10.4172/2155-9864.1000S4-003

Page 3 of 3

13. Imanaka $\mathrm{Y}, \mathrm{Lal} \mathrm{K}$, Nishimura $\mathrm{T}$, Bolton-Maggs PH, Tuddenham EG, et al. (1995) Identification of two novel mutations in non-Jewish factor XI deficiency. Br J Haematol 90: 916-920.

14. Alhaq A, Mitchell M, Sethi M, Rahman S, Flynn G, et al. (1999) Identification of a novel mutation in a non-Jewish factor XI deficient kindred. Br J Haematol 104: 44-49.

15. Quélin F, Trossaërt M, Sigaud M, Mazancourt PD, Fressinaud E (2004) Molecular basis of severe factor XI deficiency in seven families from the west of France. Seven novel mutations, including an ancient Q88X mutation.J Thromb Haemost 2: 71-76.

16. Seligsohn U (2009) Factor XI deficiency in humans. J Thromb Haemost 7 Suppl 1: 84-87. 